\title{
HELAL KAVRAMININ EĞITTIMDE YERİ VAR MIDIR?
}

\begin{abstract}
İsmail AYDOĞAN*
Kırıkkale Üniversitesi, Eğitim Fakültesi, Eğitim Bilimleri Bölümü, Kırıkkale, Türkiye

MAKALE BILLGISI

Geliş tarihi: 13 Nisan 2021 Düzeltme tarihi: 25 Mayıs 2021 Kabul tarihi: 11 Haziran 2021

Anahtar Kelimeler: Helal, eğitim, yasal

ÖZET

Eğitim, insanın düşünce ve davranışlarını kültüre uygun hale getirme işidir. Öğretim, bu faaliyetin bilgi kısmını oluşturur. Ancak öğretimin varlığını borçlu olduğu yer, kültürdür. Öğretimin her alt alanı, kültür düşüncesine göre anlam ve mana kazanır. Seküler eğitimin insanı anlam ve mana açısından itibarsızlaştırması, kültürün hayatın dışına atılmasıyla olmuştur. Kültürün önemli bir kavramı helal kavramıdır. Bu çalışmada, eğitim ve öğretime dair düşünce ve kazanımların helalle ilişkisi kurulmaya çalışılmıştır.
\end{abstract}

Keywords:

Halal, education, legal
DOES THE CONCEPT OF HALAL HAVE A PLACE IN EDUCATION? ABSTRACT

Education is the study of adapting human thoughts and behaviors to culture. Teaching forms the knowledge part of this activity. But where teaching owes its existence is culture. Each subfield of teaching gains meaning according to thought of culture. Secular education has discre-dited people in terms of meaning by excluding culture from real life. An important concept of culture is the concept of halal. In this study, it has been tried to establish a relationship between the ideas and gains about education, and halal.

\section{Giriş}

Helal, İslami anlamda yapılması serbest olan eylemlerdir. Dinin yasaklamadığı şeylerdir. Bir başka ifadeyle sınırları din tarafindan çizilmek koşuluyla sergilenen iradi eylemlerdir. Helalin, sadece para ve yiyecekler üzerine kurulu bir algısının olduğu yanıltıcıdır. Her şeyin helali olur. Misal, konuşmanın helali olduğu gibi, yürümenin de helali olur. İletişim kurmanın helali olduğugibi, bir sınıfı yönetmenin de helali olur.
Tıpkı gülmenin, ağlamanın, şarkı söylemenin vb. helali olduğu gibi. Helal kavramının daraltılmasında Yahudi çabalarının olduğunu gözden kaçırmamak gerekir. Çünkü helal kavramı sadece Yahudilikte yiyeceklerle ilgilidir. İslam'da helalin yiyecekle ilişkilendirilmesi ise insanın ruhuyla ilgili bir meseledir. Çünkü helal yemek, yemeği helalinden yemek, insanı ahlaklı kılar. Helalin amac1, yemeğin ötesindeki hayata nizam vermek içindir (Koca, 1998; Kurt, 2010; Demirci, 1998).

*İsmail AYDOĞAN, E-mail: iaydogan124@gmail.com Orcid: https://orcid.org/0000-0002-5447-4741 
İslam'da helal kavramı, bir evin "cümle kapıs1" konumundadır. Nasıl ki cümle kapısı, bir binanın ana giriş yeri ise, helal de her işin ilk kapısıdır. Kapısız eve girilmez. Helal olmayan işe de doğal olarak girişilmez. Bir çocuğun eğitimi için, dikkat edilecek hususlardan biri eğitimin helal olup olmaması olmalıdır. Değilse o kapıdan girilmez, girilirse de, orada helal aranmaz. Helal, bir düşünme biçimi olarak cümle kapısı konumundadır.

Tarih 20. yüzy1lı her hâlükârda farklı yazacaktır. Çünkü bu yüzyıl, dinlerin, toplumdan ve insandan kovulduğu asırdır. Dinin belirleyici olmaktan çıktığı bu yüzyılda, eğitim de dinin kapsamı alanından çıkmıştır. Böyle olunca eğitim, diğer alanlar gibi seküler hale gelmiştir. Sekülerizm ise, kültürün ve özellikle dinin belirleyici olmadığ hayat tasavvurudur.

Türkiye'nin batılaşması ve insanımızın da batılılaşması sonucunda eğitim, hayatın diğer kurumları gibi, dinin belirlediği haramhelal kategorisinden çıkmış, yasal olan-olmayan kategorisine, oradan da işe yarar-işe yaramaz evresine düşmüştür. Bugünün insanı pragmatizmin kulvarında oportünistçe yaşarken, mâsivanın boyunduruğu altına sokan bir eğitimi yüceltmektedir. Bu yüceltmede elbette, Batı felsefesinin Fransiz ihtilaliyle tecavüz edilmesini atlamamak gerekir. Böylelikle 20.yüzy1l, fikirler nezdinde tecavüz kültürünü oluşturma görevinin okullara yüklendiği asırdır. Amerikan pragmatizmi ve oportünizmiyle okullar, fikir tecavüzünün kültürünü oluşturmuştur. Bu tecavüz kültürüyle helalin miadını doldurmuş olduğu söylenebilir. Çünkü artık "tanrı" devreden çıkarılmıştır. Tanrının olmadığ 1 yerde de ne haram vardır ne de helal.

Pozitivizm fikirden kültürün arındırılmış hali olduğundan, eğitimin pozitivistleşmesi onun kültürsüzleşmesi demektir. Bu da doğal olarak eğitimi, kültürün omurgası olan dinden uzaklaştırmak olduğundan helalharam kategorisinin dışında düşünmek demek olmaktadır. Bu nedenle eğitimi helalsiz düşünmek pozitivist düşünmenin sonucudur.

Her ne kadar helal kavramı İslami bir kavram olsa da anlam açısından meseleye bakıldığında dinlerin müsaade ettiği alan olarak genişletmek mümkündür. Bu bağlamda eğitimin helali demek, eğitim sürecinde ve sonucunda kültürel düşünme biçimine sahip olmak demektir. Örneğin bir Fransız çocuğu, Fransız eğitim sisteminden geçtiğinde, ondan beklenen Fransız kültürüne göre düşünme ve yaşama becerisine sahip olmasıdır. Böyle olduğunda Hristiyan ölçeğinde helal bir eğitimden geçmiş olur. $\mathrm{Bu}$ durum bir Japon, Çin, Rus veya bir Hristiyan, Yahudi ve Müslüman için de geçerlidir.

\section{Eğitimin Helali Mümkün mü?}

Bir düşünme biçimi olarak helal eğitim, kültüre göre düşünme biçimi oluşturma gayretidir. Bu düşünme biçiminde belirleyici olan şey kültürdür. Örneğin bu eğitim sisteminden mezun olan bir inşaat mühendisi için evlerin güneye bakmasının nedeni, güneşten yararlanmak değil, güneyde yer alan Kâbe'ye doğru olmasıdır. Kâbe, Müslümanların ne yaparlarsa yapsın vazgeçemeyeceği yöndür. Her kapı, özellikle cümle kapıs1, Kâbe'ye bakar. Ve muhite gelen yabancı, Kâbe'nin yönünü rahatça, kimseye sormadan bilir. Eğitimin pozitivistleşmesi demek, evlerin güneye doğru yapılmasının nedeninin güneşten yararlanma amacı gütmesi demektir. Oysa güneşten yararlanmak asıl neden değil, tali nedendir. 
Aynı şekilde biyoloji bilimi, sadece insan vücudunu tanıma bilimi değildir. Biyolojiyle insan, kâinatın minyatüründen hareketle kâinatı tanıma ilmini edinir. Kimya bilimi bir irfan yolu; fizik ahlakın öğretildiği alandır. Matematik dürüstlüğün alanı olurken, Edebiyat (şiir) ruhun tekamüle yol alması, olgunlaşmanın erkanıdır. Tarih bilinçten başka bir şey değildir. Müzik, İlah'a yakarış; beden eğitimi o ilahın emirlerini yerine getirmek için insana emanet edilmiş bir sığınaktır. Eğitim ve onu oluşturan unsurlar, bağından ve bağlamından koparıld1ğında, yani sekülerleşip pozivistleştiğinde, anlam ve mana ilimden koparılmış olur. Helal eğitim, bu anlamın var olduğu eğitim demektir. Çalışmayı ibadet yapan şey, yapılan iş ve eylemleri değildir, onun gayesidir. Gayeyi helal yapan ise niyetlerdir. Mesela, terör örgütlerinin militanlarını eğitmesi de eğitimdir, komutanların askerleri eğitmesi de eğitimdir. Askerin eğitimini teröristin eğitiminden ayıran şey, eğitimin şekli, yöntemi hatta içeriği değil, niyeti ve gayesidir. Aynı şekilde bir insanın karısını/kocasını öpmesi ile nikâhı olmayan birini öpmesi arasında eylem olarak bir fark yok ama niyet farkı vardır. İşte bu fark birini helal yaparken diğerini haram yapar. Son bir örnek daha vermek gerekirse, iyilikle sadaka arasındaki farklılık eylemsel değil niyetten oluşur.

İşte bu örnekler, eylemlerin sadece eylem olarak bir anlam ifade etmeyeceğini, niyetlerin ve gayelerin onları anlamlı ve manalı hale getireceğini ortaya koymaktadır. Gayesi halis olmayan, niyeti kültürden kaynaklanmayan, daha açık bir ifadeyle, ulvi ve müteal değerlerden neşet etmeyen düşünce ve eylemler boşluğa atılmış nesneler gibidir. Nadiren işe yaradıkları görülebilir, ama bu onun helalliğini göstermez.

Eğitimin helalliği niyetten gelir. Şu halde niyet, bizim hedeflerimizi, amaçlarımızı, ideallerimizi, uğraşlarımızı ve çabamızı belirleyen, bunlara mana ve anlam katan özdür, mayadır. Eğitimi helal kılan bu niyet, edep ve terbiyenin kucağında, göğsünde veya gönlünde yaşar. Bir başka ifadeyle eğitimin yurdu, vatanı edep ve terbiyedir. Niyet, bu yurdun bayrağıdır.

Peki, edep ve terbiye nedir? Edep, en geniş anlamıyla eğitimdir. İçinde öğretimin de yer aldıği eğitimdir. Terbiye ise bunun öğretimidir. Edep ve terbiye, İslam kültürü, geleneği, ahlakı, düşünme ve yaşama biçimi olup, buna sahip olan insana edepli veya terbiyeli insan denir. İslam tasavvurunda eğitimli insandan maksat, edepli ve terbiyeli olmasıdır. İşte helal olan eğitim bu eğitimdir. Aksi halde, edep ve terbiye dışı (karşı değil dışı) eğitim-öğretim, pragmatist bir eğitimdir. Pragmatizmde yararlı olan iyidir mantığı önemlidir. Bir şeyin yararlı olmasıyla hayırlı olması aynı şey değildir. Bir şeyin hayırlı olup olmadığı net olarak bilinemez. Çünkü o şeyin görünen yanı insanın, görünmeyen yanı Allah'ındır. Bu nedenle süreç insanın, sonuç Allah'ındir.

Seküler eğitimin kültür dişılığı onu pragmatist ve sonuç odaklı yapmıştır. Bu pragmatizm ve sonuç odaklılıkta bir bilgi, insanın işine yarıyorsa iyidir, değilse onu öğrenmeye hacet yoktur. Oysa ilim, bir işin gerçeğini öğrenme işidir, surete takılıp kalmadan asla olan yolculuktur. Bir başka ifadeyle "şey”lerin aslını öğreten ilim helal olan eğitimdir. Helal kavramının ilginç bir özelliği amaç kadar aracında meşru olmasıdır. Araç, amaç gibi meşru değilse, yapılan iş doğru bulunmaz. Misal, temizlenmek kadar temizlenecek suyunda temiz olmas1 gerekir. Bu iş herhangi bir suyla yapılamaz. Başarılı olmak amaç ise, bu, kopya çekerek yüksek not almakla olmaz. 


\section{Helal Olanla Yasal Olan Aynı mıdır?}

Bir şeyin helal olması dini bir mesele olurken, yasal olup olmaması kanuni bir meseledir. Her yasal olan helal olmadığı gibi her helal olan da yasal değildir (Alatlı, 2015). $\mathrm{Bu}$ ayrım, kültürlerin ve dinlerin insan ve toplum hayatında belirleyici olmaktan çıkmasıyla olagelmiştir. Sekülerizm, dini insanın bir şubesi olarak tahsis etmesi nedeniyle insan düşüncesi, hayatı parça-bölük haline geldi. Her insanda ikilik oluştu; ikili düşünce, ikili yaşam vb. Eğitim sistemleri de bu gelişmelerden etkilendi. Sanayi devrimi ve Fransız ihtilali ile oluşturulan seküler modern hayat, okullar eliyle insan hayatını dizayn edinmeyi amaç haline getirince, insan da, var olan ve dayatılan hayatları birlikte götürmek zorunda kaldı. Böylelikle oluşan bu ikili hayat bir süre sonra normalleşti. Ardından var olan hayat çekilirken, dayatılan hayatın alanı genişledi. Uzun yılların ardından batılı ülkelerin şimdiki yaşamı, yani modern seküler hayatı, tek seçenek oldu. Ancak batıyı takip eden balkan, Ortadoğu, Afrika, Asya ülkeleri açısından bu ikilik uzun süreden beri devam etmektedir. Türkiye de bu ülkelerden biridir.

Bugün Avrupa ülkeleri Hristiyanlığa mahsus helal olan-olmayan şeklinde bir düşünce biçimini değil, yasal olan-olmayan şeklindeki seküler düşünme biçiminin oluşturduğu ahlakın içinde bulunmaktadırlar. Eğitimlerini de bu düşünme biçimine göre yapmaktadırlar. Türkiye gibi ülkelerde ise helal-yasal ikiliği varlığını devam ettirmektedir. Bu da halk-devlet bütünlügünün sağlanmasına engel olmakta, aynı zamanda, eğitimdeki niteliksizliğin önemli nedenlerinden birini oluşturmaktadır. Mesela halkın ya da sıradan insanın kişisel yaşamında helal düşüncesi belirleyici iken, devletle (kurumlarla) ilişkisinde yasa önemli hale gelmektedir. Hatta eğitimde öğretilen sıradan bir bilginin -örneğin çevrenin temiz tutulması düsturunun- hayata geçememesi, eğitimin seküler bakış açısının sonuçlarındadır. Yasal olan bir şeyin müteal değerlerle bağlantısızlığın doğal sonucu olan bu seküler düşünce biçimi müfredatın içine sindiğinden, öğretim, kişisel hayatında helal düşünce biçimini temel alan insan tarafindan sathi bir mesele olarak görülmekte, hayatın içine dercedilmemektedir. Bu da okulda olan okulda kalır düşünme biçimini geliştirmektedir. Bu durum, okulun insan ve hayat üzerinde etkisizliğinin önemli nedenlerindendir. İşte bu nedenle trafik bilgisi var ama trafik kurallarına uyma az, yalanın kötülüğü bilgisi var ama yalan söylemekten uzaklaşma gayreti azdır. Bilginin pratiğe dökülmemesi bu ikiliğin varlığı nedeniyledir.

Elbette helal-yasal ikiliğinde kazanan taraf, çok yüksek ihtimalle yasal düşünme biçimi olacaktır. Nitekim 1980'li yıllardan itibaren olan da budur. Türkiye gün geçtikçe yasal düşünme biçimine, bir başka ifadeyle seküler düşünce ve yaşama biçimine doğru evrildiğinden, helalin belirleyiciliği azalmaktadır. Ancak tarihi ve kültürel mirası, Türkiye'nin seküler hayat tarzı üzerine kurulu bir eğitimi benimsemeyecektir. Bu nedenle eğitimin kimliği, önünde sonunda, helal kavramının ikliminde, yani kendi kültürünü temel alan bir eğitimde var olacaktır. İçinde bulunduğumuz halin bu öngörüye tezat olması, bu gerçeğin olmayacağ sonucunu yol açmaz. Çünkü gerçeğin ne çoğunluğun desteğine ihtiyacı vardır ne de sönüp ortadan kalkacağ1 vardır.

\section{Eğitimin Açmazı ve Helal Tasavvuru}

Eğitimin kurumsallaşması Abbasi döneminde başlar, Selçuklu döneminde yaygınlaşır, Osmanlı döneminde de 17.yüzyılın başlarına kadar kültürel işlevini hakkıyla 
yerine getirdiği söylenebilir (Çelebi, 2013). Batılı dünyada eğitimin kurumsallaşması ise 12 yüzyılda başlar, 16.yüzyıla kadar emekler, 16.yüzyılda ana yoldan (kültürel bağlamdan) sapar, 17.yüzyıldan itibaren ise saptığı yolu (sekülerliği) genelgeçer yol yapmaya çalışır. Batılı kimi eğitimcilerin eğitimde kurumsallaşmanın başlamasıyla eğitimin insanın doğasını bozduğu tespiti (Illich, 2019) doğru bir tespit değildir. İnsanın doğasını bozan şey, eğitimin kurumsallaşması değil sekülerleşmesi ve pozitivizmin girdabına sokulmasıdır. İşte bu eğitim 18.yüzyıldan beri sadece bizim ülkemizde değil, hemen her ülkede insanı boğmaktadır. Kültürü merkez yapmayan, insanı öğrenme obezi yapan ve başarı denen tuhaflığın cenderesinde insanı öğüten bu eğitim sisteminin hem kendisini hem de insanı bir açmaza sürüklediği açık bir sırdır. Bu açmaz, insanı sadece duyarsızlaştırmıyor, aynı zamanda ahlak, samimiyet ve merhametten de azade kiliyor. Aynı zamanda bu azadelikle insan, miyarını da kaybediyor. Sonuçta olan şey, narsist, ş1marık, yönsüz, kültürsüz bir eğitim ve insandir.

Eğitimi bu açmazdan, insanı da yukarı doğru düşmekten kurtaracak olan şey müteal değerlerle örgülü, kendini bilen ilmin yurduna terfi ettirmektir. İnsanı anlamın ve mananın yurdunda mukim kılacak eğitim, ne öğreten ne bildiren ne bulduran ne de sorduran eğitimdir. Bu eğitim, zihinsel gelişim için hafizayı, duygusal gelişim için vicdanı, ahlaki gelişim için merhameti temel alır. Ayrıca tüm bunların gelişimi için hakikate boyun eğer. İşte o hakikat, helalin yoğrulduğu niyetin, onun tecessüm ettiği cömert bakışın, şükreden bir kalbin toprağında yeşerecektir. Bir başka ifadeyle aklına düşeni değil, gönlüne ve vicdanına düşeni temel alan helal tasavvurunun çerçevesini çizdiği eğitimin dünyasına evet diyebilmektir.

\section{Sonuç ve Öneriler}

Sanayileşme sonrası Avrupa düşüncesinin kültür dışına itilmesi, Fransız ihtilaliyle seküler yaşamın oluşması hayatın doğal akışıyla olagelmiş olgular değildir. Sanayileşme ile insan gücüne duyulan ihtiyaç, köyden şehre göçü doğal olarak başlatmış değildir. Sanayileşmenin konağı mesabesindeki fabrikanın cazibesini oluşturan, tarım üretiminin teşvik edilmemesi de göçün önemli nedenleri arasındadır. Dinin ve onun uygulaması denebilecek kültürün /geleneklerin toplumsal yaşamda önemsizleşmesinin nedenleri arasında sanayileşmeyle kurulan şehirler ve oradaki fabrikaların yeni bir çalışma sistemini zorunlu kılması küçümsenmemelidir. Fransız devrimi, nihayetinde kültürel bir devrimdir. Çünkü bu devrimle yeni bir hayat biçimi dayatılmıştır. Din ve kültür insan ve toplum yaşamından çıkarılması akıl ve bilimin yüceltilmesinin de sonucunda olduğunu bilmek gerekir. Sanayi devrimi ve Fransız devrimi her iki olgunun (din ve kültür) akıl ve bilim karşısında mağlup olmasıdır. Elbette akıl insanda her zaman vard1. Ancak geleneksel devirlerde akıl kültüre, dine, kısaca Tanrıya bağlıydı. Devrimler sonrası oluşan modern hayatın aklı ise, bağsız bir akıldır. Akıl gibi bilim de her zaman vardı, ama modern dönem bilimi, bu aklın çocuğudur. Bağsız, bağlantısız bu akıl, helalin değil yasal olanın yüceltilmesini sağladı.

Gelinen noktada helal, kendi değerli mecrasına çekilmiş gözükmektedir. Ama bunun ortadan kaldığı, bir buz gibi güneş karŞ1sında eriyip gittiği şeklinde düşünmek, ilerlemeci modern bilim anlayışının öne sürdüğü yanlış argümanlardır. Eğitimin helali, kültürün mecrasında yürüyen aklın, insanın kaçamadığı vicdanın, hakikati anlamak için çabalayan bilimin gönlünde yazılan güftenin bestelenmesiyle oluşan şark1lar gibidir. 


\section{Kaynaklar}

Alatl1, A. (3 Ocak 2015). Her yasal hak helal değildir. https://www.yenisafak.com/hayat/her-yasal-hakhel\%C3\%A2l-degildir-2056951. Son erişim tarihi: 02.02.2021.

Çelebi, A. (2013). İslam'da ĕgitim öğretim tarihi (A. Yıldırım, Çev.). İstanbul: Damla Yayınları.

Demirci, K. (1998). Helal. Türkiye Diyanet Vakfi İslam Ansiklopedisi içinde (17.cilt s.173-175). İstanbul: Türkiye Diyanet Vakfı İslam Ansiklopedisi.

Illich, I. (2019). Okulsuz toplum. (Çev: M. Özay, Çev.). İstanbul: Şule Yayınları.

Koca, F. (1998). Helal. Türkiye Diyanet Vakfi İslam Ansiklopedisi içinde (17.cilt s.175-178). İstanbul: Türkiye Diyanet Vakfi İslam Ansiklopedisi

Kurt, A.O. (2010). Yahudilikte koşer ve koşer ekonomisi. C.Ü. ilahiyat Fakültesi Dergisi, XIV-2, 103-149. 